\title{
EXPERIÊNCIA GERACIONAL E IDENTIDADE DE FRONTEIRA: representações sociais sobre o rural amazônico.
}

\section{GENERATIONAL EXPERIENCE AND BORDER IDENTITY: social representations about the Amazonian rural.}

\author{
Fábio Fonseca de CASTRO ${ }^{1}$
}

Resumo: O artigo reflete sobre a conformação da visão de mundo de um grupo de jovens de uma cidade do sudeste do Pará, Parauapebas, sobre a experiência de viver numa fronteira amazônica. As visões do senso comum - por um lado a promessa de riqueza e desenvolvimento; por outro, a imagem de crise e violência - são contrapostas pelas representações efetivamente construídas por esses jovens nas suas vidas cotidianas, conformando uma experiência geracional marcada pela sensação de transitoriedade. A discussão se produz com base em pesquisa a respeito das representações sociais de um grupo de 38 alunos de um curso de Comunicação, com habilitação em Jornalismo. Em sua maioria, esses alunos nasceram fora da região amazônica e experienciaram a situação social identificada por diversos autores como sendo marcada pelas dinâmicas conflitivas e transitórias que caracterizam os processos sociais de ocupação do território amazônico - situação essa muitas vezes identificada como um vazio ontológico. Testamos essa percepção, contrapondo-a com a experiência cotidiana efetiva dos jovens. Para fazê-lo, recolhemos suas representações sociais a respeito do lugar em que vivem, indagando em que medida suas percepções de mundo e a respeito do rural amazônico são mediadas pelos tecidos intersubjetivos e midiáticos que conformam a "fronteira" amazônica como um espaço condenando à transição e à eventualidade.

Palavras-chave: Fronteira; Amazônia; Jovens; Identidade; Comunicação.

Abstract: The article reflects on the conformation of the world view of a group of young people from a city in the southeast of Pará, Parauapebas, about the experience of living on an Amazonian border. The visions of common sense - on the one hand the promise of wealth and development; on the other hand, the image of crisis and violence - are contrasted by the representations effectively constructed by these young people in their daily lives, forming a generational experience marked by the sensation of transience. The discussion is based on research about the social representations of a

\footnotetext{
${ }^{1}$ Doutor em Sociologia pela Universidade de Paris V, com pós-doutorado em etnometodologia pela Universidade de Montreal. Professor e pesquisador do Programa de Pós-graduação Comunicação, Cultura e Amazônia e do Programa de Pós-graduação em Desenvolvimento Sustentável do Trópico Úmido, ambos na Universidade Federal do Pará. Professor visitante do Departamento de Sociologia da Universidade de Cambridge. E-mail: fabio.fonsecadecastro@gmail.com
} 
group of 38 students of a Communication- Journalism course. For the most part, these students were born outside the Amazon region and experienced the social situation identified by several authors as being marked by the conflicting and transient dynamics that characterize the social processes of occupation of the Amazonian territory - a situation that is often identified as an ontological void. We test this perception by contrasting it with the actual daily experience of young people. To do so, we collect their social representations of where they live, inquiring about how their perceptions of the world and the rural Amazon are mediated by the intersubjective and media tissues that make up the Amazonian "frontier" as a space condemning to the transition and to the eventuality.

Keywords: Border; Amazon; Youth; Identity; Communication. 


\section{míDiA

Identidades na fronteira amazônica

Este artigo reflete sobre a experiência geracional de universitários de comunicação da "fronteira" amazônica. Nosso objetivo é perceber como se formam as representações sociais que produzem sobre o espaço que ocupam na Amazônia - e, por meio delas, seus vínculos sociais geracionais e suas identificações espaço-temporais. Mais especificamente, procuramos compreender como eles constroem sua inserção, na complexidade do espaço amazônico, a partir de uma experiência social que se dá num território de ocupação recente e dinâmica, o município de Parauapebas, no Pará. O fato de serem alunos de comunicação, e futuros jornalistas, nos leva a pressupor que a sua compreensão, bem como a representação que fazem do espaço no qual se inserem, constitui um elemento maior da sua visão de mundo e do seu ethos profissional.

Os atores sociais observados são 38 universitários de uma turma especial - única - do curso de Comunicação, habilitação em Jornalismo, oferecido por uma instituição pública de ensino superior, a Universidade Federal do Pará, na cidade de Parauapebas ${ }^{2}$. Coletamos, por meio de formulários contendo questões objetivas e subjetivas sucedidos por entrevistas semi-estruturadas individuais, gravadas em áudio e posteriormente decupadas, representações espaço-temporais da sua percepção de mundo. Procuramos perceber de que modo essa percepção produz uma representação social de sua identidade geracional e como essa representação interpreta a condição de serem amazônidas e, nessa condição, os habilita a evocar e produzir uma identidade social ou cultural.

O contexto da pesquisa se insere na perspectiva metodológica de uma etnografia da comunicação, que vimos desenvolvendo também em outros espaços amazônicos a partir dos Programas de Pós-Graduação Comunicação, Cultura e Amazônia e Desenvolvimento Sustentável do Trópico Úmido, ambos na Universidade Federal do Pará. A mostra trabalhada neste artigo foi produzida no ano de 2007 e constitui a primeira coleta de dados que realizamos com essa perspectiva metodológica. A ela, seguiram-se outras, que buscam concretizar o objetivo de compreender as intersubjetividades vivenciadas pelas populações amazônicas. Retornamos a ela, neste

\footnotetext{
${ }^{2}$ A turma especial do curso de Comunicação da UFPA em Parauapebas resultou de um convênio entre a Prefeitura municipal e essa universidade e ocorreu entre os anos de 2005 e 2009, formando 42 jornalistas.
} 


\section{míDiA

momento, dez anos passados, com uma perspectiva compreensiva e de revisão do trabalho realizado. Com efeito, damos forma de artigo de síntese a um survey realizado há dez anos e com divulgação apenas interna, em nosso grupo de pesquisa, em forma de paper. Assim, procuramos consolidar os dados coletados à luz da reflexão que desenvolvemos ao longo desse período e, quem sabe, iniciar um percurso de retorno, por meio do qual possamos, em trabalho futuro, compreender que perspectivas mudaram e que representações surgiram, da fronteira, ao menos em Parauapebas, a respeito do lugar que ocupa no subcontinente amazônico.

$\mathrm{O}$ objeto intrigante que desejamos explorar diz respeito à formação, nessas representações, da percepção desses jovens de fazerem parte de um espaço amazônico que muitos discursos, dentre acadêmicos, midiáticos e mesmo no senso comum, se compreende como sendo uma "fronteira" amazônica, uma área de imigração e de colonização recente.

Para caracterizar o que chamamos de fronteira amazônica partimos da reflexão de Otávio Velho (1979) sobre o caráter conflitivo e transitório dos processos sociais de ocupação do território amazônico. Segundo Velho, o modelo de ocupação recente da Amazônia produz um choque intermitente entre a situação social antes existente e os interesses do Estado, agente promotor central dessa ocupação. O resultado desse choque seria um espaço social e histórico marcado pela indefinição, pela crise, pela mutação e pelo transitório (VELHO, 1979: p. 76). Evidentemente a análise de Velho precisa ser circunstancializada pela ação do Estado brasileiro que decorre das imposições estabelecidas pela Constituição de 1988, bem como pela experiência social recente das populações da fronteira amazônica, porém, ainda assim, o conceito de fronteira nos parece atual para caracterizar a experiência social desses espaços amazônicos. Com essa percepção, podemos relativizar o diagnóstico inicial, observando que a situação de anomia sugerida não deixa de permitir a constituição de redes locais e específicas de solidariedade e socialidade, e que a fronteira "em movimento" também é um espaço de produção e de reverberação de sentidos.

O debate sobre a "fronteira" e os processos de "fronteirização" na Amazônia possui uma tradição que se consolida com Becker $(2004 ; 1999 ; 1990)$ e sua discussão a respeito da ocupação desse espaço por meio de dinâmicas econômicas induzidas pelo 
Estado e associadas a fatores multiconcorrenciais derivados. Becker observa que o padrão de "integração" adotado pelo Estado desenvolvimentista brasileiro, nessa dinâmica, tinha o compromisso de "manter e expandir o processo industrial e reduzir seus laços de dependência" (BECKER, 1990: p. 11), com o que se observa uma lógica de fronteirização voltada para a uniformização.

Como colocam Celentano e Veríssimo, "o avanço da fronteira na Amazônia tem sido marcado por degradação dos recursos naturais, violência e por um crescimento econômico rápido, porém não-sustentável na maioria dos municípios da região" (2007: p. 6), um modelo de crescimento que foi chamado de "padrão boom-colapso" por Schneider et al. (2000) e que se assenta na sucessão, a um período de expansão do PIB e emprego - e de consequente valorização do IDH - por um período de violência, degradação ambiental e queda dos indicadores econômicos. Vainer (2003) e Acserald (2002), por sua vez, discutem como se produz a inserção da Amazônia no mundo globalizado.

Esse debate possui um campo simbólico que impacta sobre o senso comum e sobre a produção dos sentidos cotidianos. É a partir dessa perspectiva que nos perguntamos: o que representa, na vida cotidiana dos amazônidas, a noção de fronteira? Quais os seus símbolos, os seus sintomas? De um lado, ideias de riqueza: dinheiro circulando, grandes empresas, promessa de lucro, abundância, oferta, desenvolvimento. De outro, ideias de crise: violência, disputa pela terra, grilagem, crimes de encomenda, desmatamento, degradação ambiental. Esses dois conjuntos de representações acompanham o modelo "boom-colapso" de Schneider et al. (2000), que acima citamos. Ambos estão presentes, simultaneamente, na fronteira amazônica em movimento e ecoam nos distintos padrões de representação, dessa fronteira, pelas populações nelas presentes. Aos habitantes da Amazônia tradicional, nos parece predominar, por vias distintas, a sensação de anomia - e, assim, a sensação de vazio ontológico, que faz com que as fronteiras em questão equivalham a uma não-Amazônia. Aos brasileiros atraídos para essa fronteira, a representação é outra: não há, certamente, vazio ontológico, apenas um vazio de gente. Nos dois casos, a fronteira está em movimento: tudo muda, o tempo avança rapidamente. 


\section{míDiA

A categoria da "fronteira" que usamos corresponde a um tipo-ideal, uma tipificação de determinado conhecimento ou visão de mundo, usado tanto pelo discurso científico e técnico como pelos atores sociais das migrações amazônicas, muitas vezes influenciados pelo discurso tecnicista dos grandes projetos desenvolvimentistas do Governo Federal, por meio do qual viram justificada tanto a sua história de migração como o conjunto de experiências cognitivas associadas à sua instalação na região amazônica. Portanto, "fronteira" não é apenas uma categoria técnica, mas um modelo, uma tipificação sócio-cognitiva corrente e produtora de um campo semântico amplo.

Com efeito, o modelo de desenvolvimento da região estabelecido pelos governos militares na década de 1960 pensou a Amazônia como uma fronteira. Baseado numa perspectiva geopolítica que considerava a Amazônia como a periferia do "centro" brasileiro, esteve centrado no projeto de integração da região aos mercados produtores e consumidores nacionais e internacionais. Loureiro observa que esse modelo de desenvolvimento não apenas "ignorou e menosprezou a diversidade (...) dos ecossistemas" como também considerou a Amazônia como "uma unidade indistinta" (LOUREIRO, 2005, p. 56-57). Alguns dos resultados mais importantes desse processo foram o estabelecimento de grandes empreendimentos agro-silvo-pastoris $\mathrm{e}$ mineralógicos em de áreas do território amazônico e o incentivo descuidado à migração, para a região, de populações sem acesso à terra e ao emprego. Passadas quatro décadas do início desse processo, dentre as diversas consequências por ele produzidas, tem-se o estabelecimento de territórios que não se conectam integralmente às macro-dinâmicas regionais. Loureiro, ainda, observa a existência atual de "grandes enclaves (...) que não produzem efeitos em cadeia" (2005, p. 56-57), o que sugere a falência de um efeito sistêmico pretendido pelas políticas de integração nacional do projeto desenvolvimentista. A representação social que as populações de áreas amazônicas mais tradicionais elaboram sobre esses enclaves costuma apresentá-los como territórios caóticos, marcados pelo descompromisso com a coerência regional amazônica e pela ausência de cadeias e vínculos sociais, sobretudo no campo cultural. Não obstante, e é isso que desejamos demonstrar com este artigo, a fronteira amazônica, qual seja ela, enclave radical ou enclave em processo de transformação, possui dinâmicas sociais 


\section{míDiA \\ eco \\ DiAno}

importantes, que, efetivamente, geram compromissos regionais, tanto no campo político como no campo cultural.

Não se teria, assim, na fronteira amazônica, o vazio ontológico - esse descompromisso com uma idealizada coerência regional - que lhe reprovam as populações de Belém e de outros espaços consolidados da região, notadamente o senso comum aí presente, mesmo em sua forma savant, quando ganha pregnância nos discursos políticos, artísticos e acadêmicos. Ao contrário, o que se verifica nela é uma vitalidade social importante, marcada por representações sociais da Amazônia e de si mesma que não são nem amorfas e nem estáticas.

Acreditamos que a experiência geracional desses 38 universitários reflete a variedade de itinerários de transcendência identitária que podem ser observados, contemporaneamente, na fronteira amazônica. Observa-se que a fronteira amazônica, geralmente interpretada por uma perspectiva macrossociológica, tem sido caracterizada, reiteradamente, como um espaço amorfo e de identidades enfraquecidas, ou como uma sociedade setorizada e com processos escassos ou problemáticos de sociabilização (BECKER et al., 1990; STOCKINGER, 2005).

Pensamos, ao contrário, que as diferenças na conformação desses tecidos sociais deixam de ser evidentes na medida em que a fronteira amazônica começa a se consolidar. Partindo em busca de uma microsociologia dessa fronteira amazônica, desejamos sugerir que as redes de solidariedade estabelecidas nesse espaço não se limitam aos tecidos orgânicos demarcados pelas proveniências de lugar e nem pelas contingências de perfil socioeconômico e/ou grupo étnico/inter-étnico. Observamos, na verdade, a existência de dinâmicas de interação simbólica e de processos de tipificação da realidade que, inferindo na produção de uma percepção coletiva da realidade social, geram práticas de socialidade e passam a produzir representações sociais da experiência social coletiva e itinerários de transcendência que acabam por permitir a produção de uma identidade.

\section{Parauapebas, fronteira amazônica}




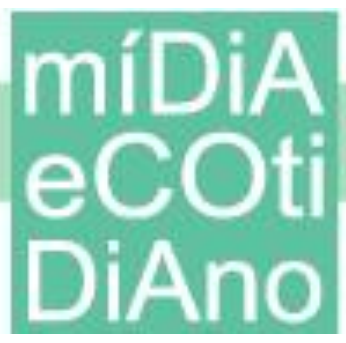

A fronteira observada neste artigo é a cidade de Parauapebas, sede do município de mesmo nome, localizada num dos territórios mais dinâmicos da fronteira amazônica: nesse município fica o complexo de mineração da Serra dos Carajás, importante enclave de produção mineral, do qual o surgimento e o crescimento de Parauapebas é inextricável.

A partir da descoberta de manganês na Serra do Sereno, contígua à Serra dos Carajás, em 1966, o Estado brasileiro iniciou um processo de ocupação desse território - inicialmente em parceria com multinacionais da mineração, mas, a partir de 1977, de maneira exclusiva, por meio da Amazônia Mineração S.A., mais tarde incorporado pela estatal Vale do Rio Doce. Em simultâneo, o Estado brasileiro desenvolveu uma série de investimentos de logística, necessários para explorar o minério de Carajás: a usina hidrelétrica de Tucuruí; usinas de beneficiamento de minerais; o porto de exportação de Itaqui, localizado em São Luís do Maranhão; a ferrovia de escoamento da produção até esse porto e, ainda, um conjunto importante de empreendimentos agro-silvo-pastoris.

O resultado desses investimentos produziu dois enclaves econômicos na porção oriental da Amazônia brasileira: um enclave de mercado, voltado para a produção de bens de troca destinados à demanda internacional, e um enclave de subsistência, destinado à produção de bens de uso e de serviços visando ao auto-sustento. Esses enclaves não constituem setores divorciados da sociedade, mas indicam dinâmicas específicas de reprodução social. No plano familiar e individual eles se sobrepõem, embora não sem conflitos, multiplicando as experiências e as práticas de contato. Além disso, pode-se mencionar, também, um terceiro enclave, mais inespecífico, mas de grande visibilidade social, que corresponde à massa de desempregados, uma população flutuante que, útil ao modelo de colonização empreendido - o qual se notabiliza pelas grandes obras, todas dependentes de mão de obra farta e barata.

Parauapebas se notabiliza por ser um vértice populacional, na fronteira amazônica, para o qual migram essas três categorias sociais: há, ali, o enclave especializado dos técnicos e funcionários da Companhia Vale, voltado para o mercado internacional; há o enclave da mão de obra de subsistência e há o enclave da população obreira, flutuante e não especializada, atraídos para o município por suas promessas de riqueza. 


\section{míDiA

A taxa de migração para o estado do Pará variou crescentemente desde os anos 1960. Segundo dados do IBGE, essa taxa era de $14,3 \%$ sobre o total populacional, nesse ano, projetada numa média sobre todos os municípios do estado. Já em 1970 ela tinhase elevado para 18,4\%, atingindo o pico de 27,5\% em 1990 (IBGE, 2013). Enquanto porcentagem média, sabendo-se que os processos de migração tiveram dinâmicas diferentes em diferentes áreas da fronteira amazônica - por exemplo, sudeste do Pará, Transamazônica, rio Tapajós e nordeste do Pará - trata-se de um índice elevado. No caso de Parauapebas, cidade surgida nos anos 1980, como de resto em todo o sudeste do estado, essas taxas são notadamente superiores.

Em 1980, a Companhia Vale começou a construir dois núcleos urbanos na Serra: a vila residencial N5, destinada a abrigar os operários construtores da mina e das demais instalações do projeto e o núcleo residencial Serra Norte, para abrigar seus funcionários. Em 1982, começou a implantar um terceiro núcleo residencial no sopé da Serra, dela separado pelo rio Parauapebas, que lhe emprestaria o nome. A função desse núcleo seria alojar a população vinda para trabalhar na obra da ferrovia e a população vinculada aos seus fornecedores.

Parauapebas deveria abrigar cerca de 5 mil indivíduos, mas em apenas três anos abrigava $172 \%$ a mais que o previsto inicialmente. A explosão demográfica e o vitalismo da vila acabaram superando a sua condição de espaço satélite de Carajás para convertê-la num espaço central. Em 1988, junto a Curionópolis, sua área foi desmembrada do município de Marabá ${ }^{3}$. De acordo com Coelho et al., Parauapebas evoluiu da condição de periferia do núcleo urbano de Carajás para a de centro social e político da região, num processo marcado pelo conflito (COELHO, 2005, p. 137-138).

Essas relações de poder ainda estão presentes em Parauapebas, reordenadas segundo configurações atuais mas que decorrem, todas, do modelo colonizador empreendido pelo Estado brasileiro. A formação populacional e sócio-subjetiva de Parauapebas deriva imediatamente desse modelo, centrado num capitalismo autoritário e na arrogância de um colonialismo interno do centro-sul brasileiro sobre a Amazônia.

\footnotetext{
${ }^{3}$ Mais tarde, territórios de Parauapebas seriam, por sua vez, desmembrados, dando origem aos municípios de Água Azul do Norte (1991) e Canaã dos Carajás (1994). De Curionópolis, por sua vez, surgiria o município de Eldorado dos Carajás (1991).
} 


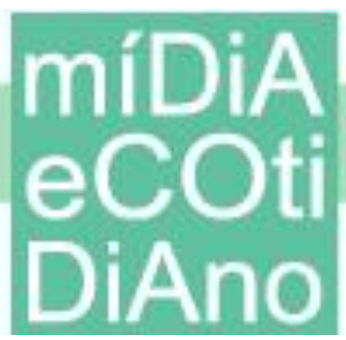

PPGMC

Atualmente (2016), a cidade tem 196.259 habitantes. Município "rico", dentre os demais do interior amazônico, sua infraestrutura é superior à média regional. Atualmente, é o sexto município do Pará em população, o terceiro em valor do PIB e o segundo em termos de PIB/per capta. Seu PIB/per capta é de cerca de R \$ 84 mil, várias vezes superior ao da media do estado, de R $\$ 8$ mil (IBGE 2016), o que ocorre em função do município receber os royalties sobre a exploração mineral da Serra dos Carajás. Em linhas gerais, é um município próspero e isso é uma condição estruturante das representações sociais que dele fazem seus habitantes.

À época da realização da enquete, em 2007, o município possuía 145.326 habitantes e um PIB/per capta de R 29.112 (estimativa IBGE 2005). O crescimento desses índices entre o período da coleta de dados e a atualidade indica o dinamismo de Parauapebas, ajudando a compreender o imaginário sobre a fronteira amazônica aqui analisado.

\section{Metodologia}

Procuramos desenvolver neste trabalho uma compreensão da forma social, centrada na observação de processos de intersubjetivação. Utilizamos o método da coleta de representações sociais, desenvolvido por Moscovici (2003), para efetuar uma percepção do campo simbólico constituído pelos entrevistados e, em seguida, recorremos a Simmel (1971) e a Schutz (1978) para melhor compreender os processos de tipificação da experiência social. Como se sabe, a proposição de Moscovici está centrada na ideia de que a produção dos sentidos se dá coletivamente, por meio de tipificações sociais, às quais compreende como representações. Partindo desse referencial, nos dedicamos à interpretação dos dados coletados, com apoio das reflexões de Mugny et Carugati (1989) a respeito da generatividade das representações sociais. A ideia central desses autores porta sobre a dinâmica de tipificação presente nas representações. Segundo eles, as representações são imagens, figuras do pensamento, que se ordenam de acordo com o sentido social que as porta, produzindo uma coerência útil.

Numa terceira etapa da observação, partimos para uma reflexão formista da ideia de fronteira amazônica. Nossa análise foi inspirada no terceiro a priori de Simmel sobre 


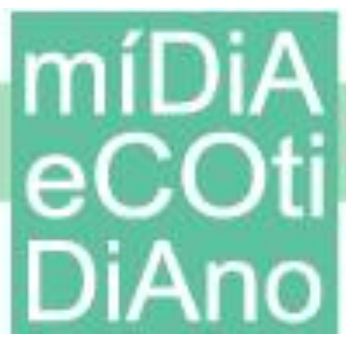

a socialidade. Simmel (1971) sugere que os indivíduos tendem a acreditar que possuem, concretamente, um lugar na sociedade, condição que produz as condições elementares para que, efetivamente, vivam em sociedade. Essa crença se produz por meio de atos de temporalização socialmente partilhados, que fazem com que os sujeitos sociais tenham, sempre, uma atitude projetiva. Seu presente, marcado por suas contingências fenomênicas, deixa-se marcar por seu futuro, ou melhor, pelo futuro para o qual se julgam predestinados, caracterizável como uma experiência temporal, ou melhor, como uma imanência fantasmática (CASTRO, 2010). Imanência porque se faz presente: o futuro se temporaliza no presente; e fantasmática porque isso se dá projetivamente.

Com base nessa reflexão, procuramos perceber a vivência social dos indivíduos entrevistados como uma temporalização, ou melhor, como uma experiência de sedimentação das tipificações socialmente recorrentes. Uma experiência que preenche de sentido o vazio da fronteira amazônica. O que desejamos demonstrar é que a fronteira amazônica não é aquele vazio ontológico, sugerido pelo senso comum das áreas tradicionais da região, pelo pensamento conservador e, também, por uma sociologia mais processual e objetivista. Pode-se compreender essa ideia de vazio ontológico com um tipo-ideal, que usamos para descrever a impressão que as populações das áreas de ocupação mais tradicional da Amazônia têm dos espaços regionais de ocupação recente. Trata-se de uma representação social do homem da fronteira amazônica como desprovido de identidade e de "amazonidade", uma projeção ideológica carregada de desprezo e talvez de despeito que mostra, igualmente, um profundo desconhecimento da realidade dinâmica da ocupação contemporânea desse espaço. E é nesse sentido que desenvolvemos nossa interpretação por meio da noção de experiência geracional: a experiência geracional dos entrevistados não é um vazio ontológico, posto que produz identificações sociais.

\section{O universo pesquisado}

No universo de 38 indivíduos entrevistados, tem-se 30 mulheres (79\% do total pesquisado) e 8 homens (21\%). A maioria deles (35\%) estava na faixa etária de 21-23 anos. Seguem-se as faixas etárias de 24-26 anos (28\%), acima de 29 anos (17\%), 27-29 $\operatorname{anos}(14 \%)$ e $18-20 \operatorname{anos}(6 \%)$. 


\section{míDiA

Em relação à sua formação e sua atividade profissional, 2 dos 38 entrevistados já possuíam outro curso superior e outros dois tinham uma qualificação técnica. Desse total, $29(76 \%)$ exerciam uma atividade profissional e $9(24 \%)$ eram estudantes em tempo integral. Desses 9, apenas um se descreveu como desempregado. Dentre os que trabalhavam, 13 (33\%) eram auxiliares administrativos em empresas do setor privado, inclusive da Vale, 4 (11\%) eram funcionários públicos, 4 (11\%) eram técnicos especializados e $1(3 \%)$ era comerciante. Outros 7 entrevistados $(18 \%)$ trabalhavam já na área profissional da Comunicação, seja como jornalistas, seja prestando serviços de assessoria de comunicação às empresas locais.

Procurando compreender a sua inserção social indagamos sobre seu local de nascimento, o local de nascimento de seus pais, o ano de sua chegada a Parauapebas e a idade que tinham ao se estabelecerem no município. Dos 38 entrevistados, apenas 2 nasceram no que é hoje o município de Parauapebas. Sua procedência se repartia da seguinte maneira: 14 (37\%), aí incluídos os 2 entrevistados nascidos em Parauapebas, eram naturais do próprio estado do Pará, 9 (24\%) do Maranhão, 4 (11\%) do Tocantins, $2(5 \%)$ de Goiás e Piauí e outros 7 (18\%) nasceram em outros estados.

Percebe-se uma maioria significativa, embora não dominante, nascida no Pará o que sugere uma migração que começa a se consolidar. Porém, se projetamos sobre esses dados a procedência de seus pais, encontramos um quadro diferente, no qual apenas $26 \%$ dos indivíduos (pais e mães dos 38 entrevistados somados), o equivalente a 19 indivíduos, são paraenses.

A ideia de fronteira em processo de consolidação se define melhor quando observamos, no universo dos entrevistados, o momento em que eles se estabeleceram em Parauapebas. Sabendo que apenas 2 deles (6\%) nasceram no município, projetamos o momento de fixação dos demais em quatro períodos de cinco anos: 1981-86, 19871992, 1993-1998 e 1999-2005. Nessa projeção, observa-se que 31\% dos entrevistados estabeleceu-se na cidade no primeiro período, $17 \%$ no segundo, $19 \%$ no terceiro e $33 \%$ no quarto. Porém, considerando que oito dos entrevistados estabeleceu-se em Parauapebas nos anos de 2004 e 2005, justamente o momento em que se produziu seu exame de ingresso no curso de graduação e o mesmo foi iniciado, percebemos que $40 \%$ dos entrevistados se estabeleceu na cidade entre 1981 e 1986, ou seja, nos primeiros 
anos de existência de Parauapebas. É a parcela mais importante, observando-se uma tendência decrescente a partir de então.

Outra projeção interessante, desta vez por evocar um padrão familiar na estrutura dos movimentos de migração para o sudeste paraense, é obtida quando lançamos no gradiente a idade dos entrevistados no momento em que se estabeleceram no município. Excetuando os dois entrevistados que ali nasceram, percebemos $27 \%$ dos demais ali chegaram entre seu primeiro e seu sexto ano de vida. As camadas entre 7 e 12 anos e entre 13 e 18 anos é similar: cada uma delas responde por $19 \%$ dos entrevistados. Somando-se esses números e considerando que até os 18 anos pode-se imaginar vínculos familiares mais sólidos envolvendo os indivíduos, encontra-se uma base de $65 \%$ de indivíduos migrados no contexto provável de uma decisão familiar. Outra parcela significativa aparenta ter migrado por conta própria: $31 \%$ dos entrevistados estabeleceu-se entre os 19 e os 24 anos de idade e $4 \%$ entre os 24 e os 30 anos de idade.

Essas diferenças produzem um imaginário sobre a fronteira - e, sobretudo, sobre o papel do indivíduo na fronteira amazônica em movimento - nuançado. Comum à maioria, era a ideia de que sua estada em Parauapebas era transitória. Indagamos se pretendiam viver definitivamente na cidade e $71 \%$ dos entrevistados responderam que não. Dos restantes, 5\% condicionaram sua permanência às possibilidades futuras de trabalho e realização pessoal e $24 \%$ afirmam categoricamente que sim, considerando-se definitivamente estabelecidos na cidade. Todos, porém, demonstram uma percepção aguda de que o espaço-mundo que os envolve estava em movimento rapidamente.

Um dado, a nosso ver importante, diz respeito aos vínculos que os entrevistados mantinham com seu lugar de origem. Cerca de $61 \%$ deles afirmou possuir algum vínculo, ainda que tênue, com seus familiares e amigos no local de origem. Porém, também percebemos que o lugar de origem não constituía um polo atrator e que apenas uma parcela pequena dos entrevistados costumava retornar a esse lugar periodicamente. Ou seja, parecia haver certa disposição de permanência na sua subjetividade. Essa disposição não significa, necessariamente, uma permanência em Parauapebas, mas sim um distanciamento do lugar de origem - o que equivale, talvez, a uma permanência na fronteira. Se, como vimos, $71 \%$ dos entrevistados não pretendia permanecer em 


\section{míDiA \\ eco DiAno}

Parauapebas definitivamente, $92 \%$ deles, por outro lado, não pretende retornar a seu lugar de origem. Quantos desejarão permanecer na fronteira? E quantos têm a expectativa de estabelecer-se em zonas de povoamento mais tradicionais - do espaço amazônico ou de outras regiões? Aparentemente, essas questões incidem na própria compreensão do que seja a fronteira: um espaço-tempo no qual a melhoria de vida se faz possível, no qual se tem chances que já não existem nos locais de origem. Um espaço, em síntese, em movimento.

\section{Representações da fronteira amazônica}

Procuramos observar a representação da fronteira amazônica, nos entrevistados, por meio da interpretação que faziam do espaço-tempo em que habitavam. A parte central do formulário, explorada em seguida por meio de entrevistas individuais, continha três questões: indagamos, sequencialmente e independentemente do momento em que se estabeleceram no município, sobre como era a Parauapebas de quando lá chegaram; sobre o que mudara na cidade, no tempo presente, em relação a como ela quando lá chegaram; e, por fim, sobre como imaginavam Parauapebas em trinta anos. Solicitamos, por meio do questionário, respostas livres e sem elementos-estímulo e inventariamos, depois, os diversos campos semânticos constituídos em cada uma dessas três perguntas.

As respostas à primeira questão tenderam a evocar um espaço social crítico, perigoso e confuso. Algumas poucas vezes, também idílico, associado ao mito de uma floresta amazônica virgem e bela. Do total das respostas, inventariando a soma das expressões utilizadas para descrever "como era Parauapebas quando lá se estabeleceu", $81 \%$ delas expressavam uma ideia negativa sobre o espaço-tempo evocado, enquanto que apenas $15 \%$ expressavam uma ideia positiva.

E o que foi percebido de negativo nesse espaço-tempo? De um total de 90 imagens empregadas pelos entrevistados para descrever negativamente essa Parauapebas fixada enquanto uma imagem de fronteira, 52 delas ressaltavam as questões infraestruturas do lugar e 38 evocavam impressões subjetivas de caos e insegurança. Dentre as questões referentes à infraestrutura - ou melhor, à falta dela - 15 destacaram a ausência de pavimentação e os efeitos decorrentes, 10 mencionaram a 


\section{míDiA

ausência de saneamento, 7 a ausência de energia elétrica e 4 a carência de equipamentos educativos e de lazer. Além disso, 16 imagens evocaram aspectos gerais da urbanização da cidade por meio de expressões generalizantes, tais como "pouca estrutura", "estrutura física muito debilitada", "péssimas condições estruturais", "infraestrutura precária" e "menos urbanizada".

A seu turno, dentre as imagens usadas na evocação das impressões de caos e de insegurança, 19 mencionavam, com variedade de figuras, o aspecto urbano daquela cidade de fronteira: "um povoado", "vilarejo", "pequena vila", "vila de zona rural", "estágio inicial", "praticamente não existia", "em fase de mobilização", "ainda não era cidade", "extremamente feia", "um lugar muito feio", "empoeirada", "conglomerado de barracos de madeira distribuídos desordenadamente", "casinhas", "em processo de construção", "poucas ruas e muitas casas", etc.

Outras imagens evocam diretamente a falta de segurança: "matavam gente todos os dias", "altos índices de violência", "violenta", "inóspita”, "muitos bordéis", "bebidas e prostitutas", "covil de ratos", "sem segurança" e "o trem trazia centenas de desesperados". Outro grupo de imagens evocou o perfil da população nessa fronteira em mutação - um perfil já entrevisto nas referências sobre a falta de segurança, mas, de qualquer forma, mais específicos no que tange à descrição do tipo mais comumente descrito como o homem da fronteira e os aspectos populacionais de Parauapebas: "poucos habitantes", "pouco habitada", "muita prostituição", "pobreza", "lotado de pessoas boas e ruins", "híbrido cultural", "famílias pobres".

Como já dissemos, as respostas positivas tenderam a evocar uma floresta amazônica ainda idílica, vislumbrada fugidamente e rapidamente perdida. Assim, as imagens que descreviam um espaço-tempo positivo, no começo da vivência do indivíduo entrevistado no lugar, referia Parauapebas como "pacata", "pequena", "com grande expectativa de crescimento", e com "rios limpos", "população bem menor", "comércio crescente", sem "especulação imobiliária" e mesmo que "corria mais dinheiro".

Mesmo sabendo que, materialmente, o momento de chegada ao município foi diferente entre os diversos entrevistados, eles tendiam a partilhar uma experiência temporal comum, disposta na duração dos processos sociais e na percepção 


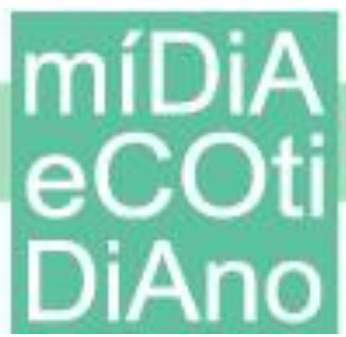

historicamente constituída e sedimentada que, em última análise, compõe a própria experiência geracional desses indivíduos. De certa maneira, todos eles são pioneiros, ainda que alguns o tenham sido involuntariamente, da fronteira amazônica.

Os entrevistados também demonstram, em suas respostas, perceber o papel da Companhia Vale como agente transformador da fronteira. Percebendo a importância dessa percepção, indagamos, nas entrevistas que se sucederam à aplicação do formulário, se sua vinda para a cidade tinha algum vínculo direto com a empresa especificamente se vieram para o município como contratados da Vale ou se vieram acompanhando algum familiar que o fora. A essa questão, 66\% dos entrevistados responderam que não e $34 \%$ responderam que sim. Porém, logo em seguida perguntamos se o entrevistado, ou alguém de sua família, possui, presentemente, algum vínculo empregatício com a empresa e essa situação se inverte: 55\% afirmou possuí-lo e $45 \%$ não. A Vale era percebida como o agente transformador principal do seu espaçomundo.

Quando projetamos a transformação do espaço de Parauapebas entre o momento de chegada do entrevistado e o momento presente - objeto da segunda questão presente na parte central do formulário - encontramos, da mesma maneira, uma descrição intensa do processo de fronteirização. Desta feita, por meio da percepção da intensidade e da agilidade na transformação do lugar. Igualmente se constituía uma temporalidade que independia do ponto de observação do sujeito - e, assim, parecia ser social, uma representação uniforme que destacava certos aspectos em detrimento de outros. E, na verdade, sempre em relação ao tempo passado, ao tempo das origens, no qual tudo era representado como o próprio caos da terra em formação.

Dessa maneira, o presente tendia a se constituir como um antípoda do passado. E o espaço entre esses dois tempos se convertia numa experiência narrativa comum a toda uma sociedade. Por oposição às 90 diferentes imagens usadas para descrever os aspectos negativos de Parauapebas no passado, tem-se agora 64 imagens positivas. Por sua vez, contra as 17 imagens positivas do passado, tem-se novas 41 imagens negativas. Como se observa, ainda não se alcançava o ponto de excelência, do ponto de vista dos entrevistados, o qual parecia estar reservado para o futuro da cidade - na construção do 
mito de uma nova terra prometida, imaginário recorrente a qualquer aventura de fronteira.

Porém, a representação de Parauapebas como um espaço de transformações rápidas e radicais em pouco espaço de tempo evoca, justamente, essa promessa, essa pretensão. Em meio às 64 imagens positivas usadas pelos entrevistados para descrever as transformações sofridas pela cidade na temporalidade passado-presente, a grande maioria apontava aspectos objetivos do progresso urbano, referentes quase todos à superação dos problemas apontados nas respostas à questão anterior. Assim é que, por exemplo, contra a memória da falta de pavimentação e de saneamento, aponta-se, no presente, grandes progressos nessas áreas. Contra as ideias de "vilarejo" e "povoado", assinalava-se, com orgulho, a expansão territorial e da malha urbanizada e, curiosamente, de maneira muito recorrente, usa-se a expressão "criação de novos bairros" para referir a essa expansão. Dentre as transformações negativas, um número expressivo assinalava o aumento populacional e o crescimento econômico desigual como realidades problemática de seu espaço social.

Por fim, as respostas à terceira questão, referentes a "como imagina Parauapebas em trinta anos", pareceram completar a representação sobre a história da fronteira como um ciclo mítico, marcado pelo destino de uma história que volta ao ponto de partida. Isso porque o futuro se fazia representar por meio de uma espécie de fábula de triunfo e morte: nenhum dos entrevistados duvidava do crescimento assombroso que Parauapebas teria em trinta anos. Sua experiência histórica assinalava esse crescimento exponencial, ágil e por vezes cruel. Nenhum deles duvida dos índices de urbanização e progresso material que seriam alcançados pelo município. Porém, da mesma maneira, nenhum deles duvida do ônus pesado que esse progresso material e urbano acarretará.

Podemos mapear as imagens construídas para responder a essa terceira questão em quatro categorias: as que se construíam objetivamente, apontando transformações positivas; as que o faziam apontando transformações negativas; as que se construíam subjetivamente apontando transformações positivas e suas congêneres negativas.

A percepção positiva estava presente em $36 \%$ do total das respostas, enquanto que a percepção negativa se encontra em $64 \%$ delas. $\mathrm{O}$ futuro descrito positivamente, respostas subjetivas e objetivas misturadas, sugere, principalmente, a "melhoria da 


\section{míDiA \\ 保 \\ DiAno}

infraestrutura urbana" (61\% das respostas positivas), enquanto $21 \%$ sugeriam o desenvolvimento social e $19 \%$ o desenvolvimento industrial.

Por sua vez, o futuro descrito negativamente, apontava índices que relembravam o caos dos primeiros tempos: um subjetivo "caos social", ao lado de uma não específica "desorganização urbana" foram as imagens mais recorrentes para descrever, de forma sombria, o futuro de Parauapebas: cada uma dessas categorias contou com $21 \%$ das respostas. Outras categorias repartem esse espectro tumultuado: desemprego (14\%); excesso populacional $(14 \%)$; criminalidade $(12 \%)$; crise na infraestrutura (12\%); crise ecológica $(6 \%)$.

Como se pode observar, essas categorias projetavam sobre Parauapebas os conflitos inerentes a uma cidade grande. Em comum a todas elas, encontrava-se a ideia, muitas vezes referida explicitamente, de que a grande missão do município, o projeto que condiciona a viabilidade do seu futuro, seria sua capacidade em superar a dependência em relação à Companhia Vale, ou seja, a percepção de que tanto o fator de atração como a exponencial crise do município se devem à ação central dessa empresa na região.

\section{Por uma tipologia da identidade de fronteira}

A percepção do espaço-tempo da fronteira, por seus habitantes, evoca noções correlatas de missão, aventura e destino. Há certa percepção teleológica na ideia de que os indivíduos que migram e habitam as fronteiras são sujeitos que rompem com o espaço-tempo tradicional. Dessa maneira, a sua condição histórica tende a produzir uma representação social da fronteira como um espaço conquistado e do conquistador como herói. Apesar da contradição lógica desse projeto, presente no fato de que a fronteira amazônica ainda está em movimento e de que a "conquista" do espaço não resultou, necessariamente, na solução para os problemas sociais que motivaram a migração, percebe-se uma ideia generalizada de que o seu esforço em participar desse processo social constitui uma forma de bem-aventurança. Ou seja, o migrante que concretiza a fronteira amazônica percebe seu papel no processo social e, por meio dessa percepção, legitima seu direito em se tornar amazônida. Por essa razão, não é concebível, para um 


\section{míDiA \\ eco DiAno}

indivíduo da fronteira amazônica, ser "menos" amazônida que indivíduos dos espaços tradicionais da região.

Por outro lado há, também, certa ilusão quanto aos aspectos cíclicos da história da fronteira, uma projeção certamente moral e muito comum a todas as fronteiras amazônicas, mesmo aquelas instituídas nos séculos XVIII e XIX: uma projeção presente na sensação de que, após um ciclo de domínio e expansão, será a vez da floresta, ou do mundo natural, se expandir contra a civilização. Há uma espécie de autocondenação, pelos atos de desbravamento e ocupação do espaço - assim associados a atos de apropriação, furto e pilhagem.

As representações do futuro da cidade de Parauapebas parecem construir essa significação contraditória: que dizer de um lugar que era "ruim", ficou "bom", mas que tornará a ficar "ruim" no futuro? Em síntese, é isso que resume a percepção da cidade por seus moradores. Apesar de todos concordarem, entre si, com o avanço rápido do tecido urbano, social e cultural do município, tendem a concordar, curiosamente, com um destino obscuro, marcado pela purgação e pela impossibilidade de conviverem, harmoniosamente, a civilização brasileira, que eles portam, com o espaço amazônico, que eles encontram no seu ato de conquista.

Há, portanto, uma coesão no espaço-tempo do passado-presente-futuro da fronteira. A fronteira é, apesar de tudo, um espaço moral. Isso resulta dela ser, sempre, em qualquer cenário histórico, um experimento social, um laboratório de limites e conexões. Vista de um espaço social contíguo, mas - aparentemente - consolidado, como Belém, a fronteira amazônica é o território do caos, do vazio, do condenável. Porém, vista a partir de sua própria experiência histórica, a fronteira amazônica é um espaço de laboratório, de ensaio.

A experiência geracional de fazer parte da fronteira amazônica conforma, no horizonte dessas dinâmicas e contradições, um feixe de representações sociais cuja ideia central parece ser a de "missão". Ser jovem e universitário de comunicação, em Parauapebas parecia sugerir que se tinha um compromisso geracional. Intuía-se uma sensação de atraso em relação à compreensão do que seja o espaço amazônico, na sua complexidade, mas não se intuía lá, de modo algum, um tecido social convulsionado e anômico - como é a representação da fronteira amazônica feita por suas populações 


\section{míDiA \\ eco DiAno}

tradicionais: povos indígenas, populações quilombolas e ribeirinhas, comunidades "caboclas" associadas a trajetórias econômicas, por sua vez associadas a atividades extrativistas normalmente não-madeireiras.

Ora, essa experiência geracional possui uma dimensão teleológica evidente: o estar-junto equivale, de certa maneira, a um ser-junto projetivo, fantasmático. Como observa Simmel (1971), os indivíduos têm certa tendência em acreditar que possuem, concretamente, um lugar na sociedade, condição que produz as condições elementares para que, efetivamente, vivam em sociedade. Essa tendência em acreditar, pensamos, equivale a uma forma social, a uma estrutura tipificante, condição que engendra, na reflexão simmeliana, um processo de sociação.

A forma social da fronteira não é uma experiência social circunscrita à experiência de vida dos migrantes, mas sim, também, uma experiência social de longue durée, ou seja, um processo histórico intersubjetivo, de dinâmica imanente, que pode ser caracterizado como uma dinâmica empática em contato com a experiência. A fronteira amazônica dialoga com a forma de todas as outras fronteiras, mas se contextualiza numa experiência geracional específica. Nesse sentido, podemos dizer que a fronteira é uma imagem-conceito, ou, recorrendo à categorização de Moscovici (2003), um themata, algo equivalente a uma memória residual, ou arquetípica que engendram, no processo social, tematizações cognitivas e lugares comuns.

No horizonte dessa reflexão, pode-se compreender a experiência geracional dos entrevistados - e, por meio dela, indagar-se sobre a experiência geracional de toda a fronteira amazônica contemporânea - como uma dinâmica social produtora de uma subjetividade comum, ou melhor, de uma intersubjetividade. Estando muito além do vazio ontológico que lhe é imputado pelas populações amazônicas tradicionais ou mais consolidadas, essa experiência geracional é produtora de sentidos e de socialidade. Mais que isso, é produtora de identificações sociais, conjunto de processos intersubjetivos que nomeiam a Amazônia de uma outra maneira, menos evidente, com menos passado, mas, certamente, não menos ativa.

Dos 38 universitários que participaram da enquete, mantivemos contato, ainda que esporadicamente, com cinco deles. Esses cinco entrevistados atuam como jornalistas, três deles em Parauapebas e os demais em outros municípios do estado do 
Pará. Por meio de um deles sabemos, informalmente, que a maioria de seus colegas de turma atua como jornalista e vive em Parauapebas ou em outros municípios da fronteira amazônica. Inferimos, com base na compreensão e no conhecimento que temos desse espaço amazônico, mas também com base no survey realizado - e, especificamente, na disposição de temporalidade que ali encontramos, na long durée das estruturas tipificantes observadas - que a experiência geracional em questão perdura, inclusive renovando-se em gerações mais novas.

Dispositivos morais - como as fronteiras - não se alteram com facilidade, e provavelmente continuam alimentando a sensação de transitoriedade desses espaços amazônicos. E, ao fazê-lo, continuam preenchendo de vida, de estar no mundo, de imanência, aquilo que, aos olhares distantes e savants da academia, das teorias do desenvolvimento, dos enunciados políticos e artísticos de Belém e mesmo do senso comum da Amazônia "antiga", mais "típica" e mais "tradicional", aparenta ser, embora por muitas outras palavras, um vazio ontológico.

\section{Referências Bibliográficas}

ACSERALD, Henri. O zoneamento econômico-ecológico da Amazônia e o panoptismo imperfeito. Cadernos IPPUR/UFRJ. Rio de Janeiro, v. XV/XVI, n. 2, p, 53-75, 2002.

BECKER, Bertha. Amazônia. São Paulo: Ática, Série Princípios, 1990.

Amazônia: Geopolítica na virada do III milênio. Rio de Janeiro: Garamond, 2004.

Os eixos de integração e desenvolvimento e a Amazônia. Revista Território. Rio de Janeiro: Laget/UFRJ, v. 4, n. 6, p. 29-42, 1999.

BECKER, Bertha K.; MIRANDA, Mariana; MACHADO, Lia O. Fronteira amazônica. Questões sobre a gestão do território. RJ/Brasília: UFRJ/UnB, 1990.

CASTRO, Fábio Fonseca de. A cidade Sebastiana. Era da borracha, memória e melancolia numa capital da periferia da modernidade. Belém: Labor, 2010.

CELENTANO, Danielle; VERÍSSIMO, Adalberto. O avanço da fronteira na Amazônia: Do boom ao colapso. Belém: Imazon, 2007.

COELHO, Maria C. N. et al. Território, cidade e entorno no espaço da mineração em Carajás/PA - Amazônia Oriental. In: TRINDADE, S. C. da et ROCHA, G. de M. (orgs) 
Cidade e empresa na Amazônia. Gestão do território e desenvolvimento local. Belém: UFPA, 2005, pp. 137-169.

IBGE (2013). Censo Populacional. Indicadores gerais por estado / séries estatísticas. Acessado em www.ibge.gov.br, a 12/08/2017.

LOUREIRO, Violeta R. Pressupostos do modelo de integração da Amazônia brasileira aos mercados nacional e internacional em vigência nas últimas décadas: a modernização às avessas. In: COSTA, M. J. J. (org.) Sociologia na Amazônia. Debates teóricos e experiências de pesquisa. Belém: UFPA, 2005, pp. 47-70.

MOSCOVICI, Serge. Representações sociais. Investigações em psicologia social, $3^{\text {a }}$ ed. Petrópolis: Vozes, 2003.

MUGNY, Gabriel; CARUGATI, Felice. Social representations of intelligence. Cambridge: Cambridge University Press, 1989.

SCHNEIDER, Robert; Arima, Eugênio; Veríssimo, Adalberto; Barreto, Paulo; Souza Jr., C. Sustainable Amazon: Limitations and opportunities for rural development. In: World Bank Technical Paper. N. 515. Environment Series. World Bank. Washington DC, USA, 2000.

SCHUTZ, Alfred. Collected papers. The Hague, Pays-Bas: Martinus Nijhoff, 1976, 3 vols.

SIMMEL, Georg. On Individuality and social forms. Chicago: University of Chicago Press, 1971.

STOCKINGER, Gottfried. A Reestruturação de relações tradicionais na Amazônia numa era de modernização forçada. In: COSTA, M. J. J. (org.) Sociologia na Amazônia. Debates teóricos e experiências de pesquisa, Belém: UFPA, 2005, pp. 105-140.

VAINER, Carlos B. Water for life, not for death. Notes for the history of movements affected by dams in Brazil. Working Papers, Harvard University, 2003.

VELHO, Otávio. Capitalismo autoritário e campesinato: um estudo comparativo a partir da fronteira em movimento. São Paulo: DIFEL, 1979. 